\title{
Physical and optical properties o of Sodium Borotellurite glasses
}

\author{
Boya Nagendra ${ }^{1 *}$, K. Narasimhulu ${ }^{2}$ \\ ${ }^{1}$ Department of physics, Rayalseema University, Karnool, India \\ ${ }^{2}$ Department of Physics, Govt. Degree college, Bellary, India \\ *Corresponding Author: nagendraboya@gmail.com,Tel.: +7676082377
}

Available online at: www.isroset.org

Received:15/Sept/2018, Accepted:19/Oct/2018, Online: 31/Oct/2018

\begin{abstract}
Sodium borotellurite glasses in the system $\mathrm{xNaF}_{2}-(20-\mathrm{x}) \mathrm{Na}_{2} \mathrm{O}-40 \mathrm{~B}_{2} \mathrm{O}_{3}-40 \mathrm{TeO}_{2}((0<\mathrm{x}<20 \mathrm{~mol} \%)$ were ready by melt quenching method. The density, molar volume and optical parameters were calculated for present glasses with increasing $\mathrm{NaF}_{2}$ concentration. The results shows that the calculated parameters strongly depends on increasing $\mathrm{NaF}_{2}$ concentration. The density reduction is due fluorine ions will enters interstitial spaces of the network and breaking B-O-Te bonds which results decreasing density of the present glasses. The thermodynamically parameters such as glass transition temperature and onset of crystallization temperature of the present glasses and were found to decrease as a function of $\mathrm{NaF}_{2}$ concentration. A shift of UV absorption edge to longer wavelength indicating reduction in the number of NBO's with increasing fluorine concentration. When $\mathrm{NaF}_{2}$ introduced in glass network, fluorine ions break the network effects in a depolymerization, i.e. B-O-Te bonds are broken and non-bridging oxygen's are made hence the decreasing band gap energy observed in the present glasses.
\end{abstract}

\section{Keywords-Glasses,Density,Optial absorption}

\section{INTRODUCTION}

The study of tellurite glasses have been increased due to variety of applications in the field of optical communication due to their remarkable properties like high refractive index, high optical non-linearity and excellent infrared transmittance [1-3]. Compare to silica glasses tellurite glasses having higher Raman gain coefficients and also find application in Raman amplifiers and waveguides [4]. It has been reported that tellurite glasses are suitable to make photonic devices due low melting temperature, thermal stability, low phonon energy and nonlinear refractive index, $[5,6]$. In the current world of technology glass material performance an important role. Among oxide glasses, borate glass is exclusive and can be used as thermal insulators and textile fiber glass. $\mathrm{B} 2 \mathrm{O} 3$ is the best glass former and borate glasses have good nonlinear optical properties [7]. Its existence in tellurite glasses result in complex glass network consisting of $\mathrm{TeO}_{4}, \mathrm{TeO}_{3+1}, \mathrm{TeO}_{3}, \mathrm{BO}_{4}$ and $\mathrm{BO}_{3}$ structural units. The adding of $\mathrm{B}_{2} \mathrm{O}_{3}$ into $\mathrm{TeO}_{2}$ glass, tellurite transforms $\mathrm{TeO} 4$ into $\mathrm{TeO}_{3+1}$ and $\mathrm{TeO}_{3}$ units and enhances the glass forming ability of $\mathrm{TeO}_{2}$. The addition of $\mathrm{B}_{2} \mathrm{O}_{3}$ also effects in decreasing $\mathrm{B}-\mathrm{O}$ co-ordination with increase in $\mathrm{B}_{2} \mathrm{O}_{3}$ concentration in borotellurite glasses [8]. Whereas, boron oxide $\left(\mathrm{B}_{2} \mathrm{O}_{3}\right)$ is excellent material for combination with $\mathrm{TeO}_{2}$ as it improves the glass quality in terms of transparency, RE ions solubility, hardness and glass stability $[9,10]$. Presently Sodium based glasses are very attractive many scientists because of low melting and easy fabrication. The glasses have also extensive applications in the field of glass ceramics, layers for optical and electronic devices, thermal and mechanical sensors, reflecting windows, IR domes, and laser windows [11-14]. Sodium borosilicate glasses have a widespread interest in a number of fields such as bioactive glasses or the storage of nuclear waste [15]. They are chemically inert, mechanically strong, and resistant to thermal shocks; these properties explain their widespread usage in the glass industry. The introduction of sodium with different glass former haven been reported in literature. The glassy system $\mathrm{Na}_{2} \mathrm{O}-\mathrm{B}_{2} \mathrm{O}_{3}-\mathrm{SiO}_{2}$ found wide application in various composite materials used in laser engineering and optoelectronics [16]. Antropova et al studied thermophysical characteristics of glasses based on the $\mathrm{Na}_{2} \mathrm{O}-\mathrm{B}_{2} \mathrm{O}_{3}-\mathrm{SiO}_{2}$ system [17]. Pacaud et al [18] also studied $\mathrm{Na}_{2} \mathrm{O}-\mathrm{B}_{2} \mathrm{O}_{3}-\mathrm{SiO}_{2}$ glasses from moliecular simulation and conclude that the impact of sodium ions on the boron coordination at room temperature is in good agreement with experimental observations. Wakasugi et al [19] studied Crystallization Tendency of $\mathrm{Na}_{2} \mathrm{O}-\mathrm{B}_{2} \mathrm{O}_{3}-\mathrm{Al}_{2} \mathrm{O}_{3}$ glassy system. They have found that the glass stability increasing with increasing $\mathrm{Al}_{2} \mathrm{O}_{3}$ concentration. Mansour [20] studied FTIR spectra binary sodium borate glasses containing $\mathrm{TeO}_{2}$. It has been observed that introducing $\mathrm{TeO}_{2}$ into $\mathrm{Na}_{2} \mathrm{O}-\mathrm{B}_{2} \mathrm{O}_{3}$ glasses may delay the expected loss of non-bridging oxygens (NBOs) in the complete glass network with the decreasing sodium oxide content. Fluoride glasses are the most important materials for 
the optical fiber technology $[21,22]$ due to their improved infrared transmission characteristics. Fluoroborate glasses composition a vital role in the development of new optoelectronic devices due to their high ionic conductivity. Kamitsos and Karakassids [21] reported spectroscopic properties of fluoride containing sodium borate glasses and discussed the role of fluorine ions in the conducting properties. Shelby and Ortolano [23] prepared of $\mathrm{NaF}-$ $\mathrm{Na}_{2} \mathrm{O}-\mathrm{B}_{2} \mathrm{O}_{3}$ glasses and studied the refractive index, density and glass transition temperatures of all glasses. Karunakaran et al [24, 25] studied Structural, optical and thermal investigations of fluoroborate glasses doped with $\mathrm{Dy}^{3+}$ ions. The variation of optical properties discussed with $\mathrm{Dy}^{3+}$ ions. Karthikeyan et al [26] also investigated Spectroscopic and glass transition of $\mathrm{Nd}^{3+}$ doped fluoroborate glasses. Fluorine ion has almost the same radius as an oxygen ion, the possibility of substitution of the oxygen ions with fluorine ions is high, but the fluorine ions could also occupy interstitial positions. Moreover, fluorine has a greater electronegativity than oxygen which would reason the breakdown of the glass network structure, the glass transition and deformation temperatures would be likely to decrease with the substitution of fluoride ions in place of oxide ions. Several studies on the introduction of fluorine ions into oxide ions were reported for ternary sodium borate glasses $[21,22,25]$.

Almost all the studies are focused on the ternary borate system. There are no reports on introduction of fluorine ions into oxide ions in quaternary sodium boro tellurite glasses. In the present work, an effort has been made for the preparation, of $\mathrm{xNaF}_{2}-(20-\mathrm{x}) \mathrm{Na}_{2} \mathrm{O}-40 \mathrm{~B}_{2} \mathrm{O}_{3}-40 \mathrm{TeO}_{2}$ glasses and study their physical and optical characterization

\section{EXPERIMENTAL}

In the current study, the glass samples of composition $\mathrm{xNaF}_{2}-(20-\mathrm{x}) \mathrm{Na}_{2} \mathrm{O}-40 \mathrm{~B}_{2} \mathrm{O}_{3}-40 \mathrm{TeO}_{2}(0<\mathrm{x}<20 \mathrm{~mol} \%)$ were ready by melt quench technique. High purity $(99.99 \%)$ sodium fluoride $\left(\mathrm{NaF}_{2}\right)$, sodium oxide $\left(\mathrm{Na}_{2} \mathrm{O}\right)$, tellurium oxide $\left(\mathrm{TeO}_{2}\right)$ and Boron trioxide $\left(\mathrm{B}_{2} \mathrm{O}_{3}\right)$ (all Sigma Aldrich) were used as initial materials. A batch of $15 \mathrm{~g}$ of the above high purity chemicals in powder form was considered, well mixed and melted in a silica crucible in the temperature range $1200-1250{ }^{\circ} \mathrm{C}$ subject on the glass composition in an electrical furnace for about $30 \mathrm{~min}$. The melt was swirled frequently until a bubble free clear liquid was formed. The resulting melt was then transferred into a stainless steel mould warmed to $200{ }^{\circ} \mathrm{C}$ and pressed with another steel disc conserved at the same temperature. All the glass samples were annealed at $200{ }^{0} \mathrm{C}$ for a duration of about $12 \mathrm{~h}$.. For samples taken from different regions of the bulk specimen, the absence of any Bragg peaks in the X-ray diffraction pattern complete that the ready glasses are amorphous.

The room temperature density $(\rho)$ of the glass was determined by the standard principle of Archimedes by means of xylene as the buoyant liquid. The thermal performance of the glass samples was examined using a differential scanning calorimeter (Mettler-Toledo: TGA/DSC1/1600HT). Samples in the form of powder balancing about $15 \mathrm{mg}$ were sealed in aluminum pans and scanned with a heating rate of $10{ }^{\circ} \mathrm{C} / \mathrm{min}$ from 30 to $600{ }^{\circ} \mathrm{C}$ in dry nitrogen atmosphere. The glass transition temperature (Tg) and the crystallization beginning temperature (Tx) were determined based on the DSC curves using the onset method. The uncertainty in $\mathrm{Tg}$ and $\mathrm{Tx}$ are $\pm 0.1{ }^{\circ} \mathrm{C}$. The room temperature optical reflectance and transmittance spectra for all the polished glass samples were recorded on a JASCO model V-570 UV-vis-NIR spectrometer in wavelength region of 200 to $1000 \mathrm{~nm}$. The band position is measured with an accuracy of $\pm 1 \mathrm{~nm}$.

\section{RESULTS AND DISCUSSION}

X-ray diffraction picture of the current glass samples are shown in Fig.1. The above figure shows no continuous or discrete sharp peaks but show wide halo, which reveals the features of amorphous glass structure.

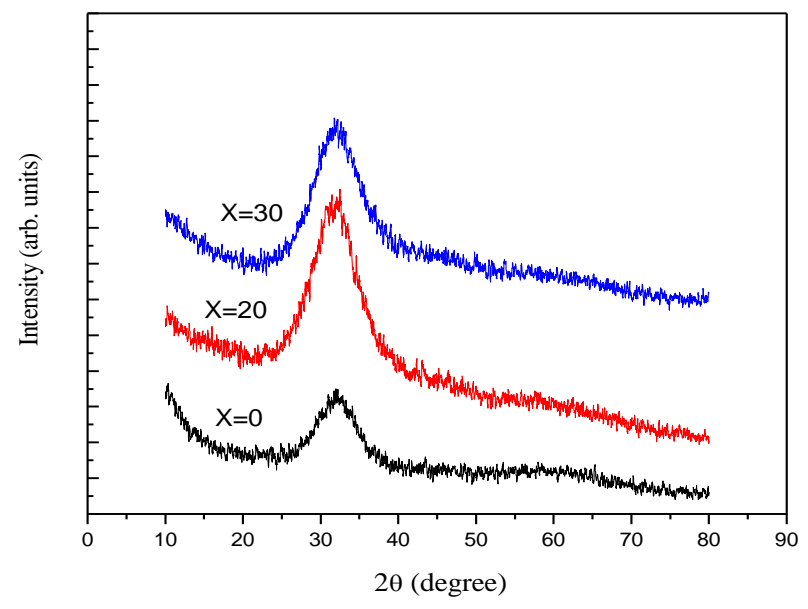

Figure 1. XRD spectra of present glasses

The density and molar volume was calculated by the formula

$$
\rho=a * 0.86 /(a-b)
$$

where $\mathrm{a}$ and $\mathrm{b}$ are the weights of the glass sample measured in air and xylene, respectively. The density of xylene at room temperature is $0.865 \mathrm{~g} / \mathrm{cc}$.

$\mathrm{V}_{\mathrm{m}}=\mathrm{M} / \rho$

Where $M$ is the average molecular weight of the glass and $\rho$ is its density.

The density of the existing glass system varies from 3.944 to $3.824 \mathrm{~g} / \mathrm{cc}$ and shown in table 1. Figure 2 shows the variation of density with $\mathrm{NaF}_{2}$ concentration. The density reduction of the present glasses with $\mathrm{NaF}_{2}$ concentration may be due to the low density of $\mathrm{NaF}_{2}$ compared with that of $\mathrm{NaO}$. The 
density decrease in the contemporary glasses can be described through the bond formation in present glasses. An significant chemical feature of Te atoms is their increasing valence from 3 to 4 . But Boron has poor electron valence, when $\mathrm{B}_{2} \mathrm{O}_{3}$ joint with $\mathrm{TeO}_{2}$ when a modifier $\mathrm{Na}_{2} \mathrm{O}$ is added, the modifier ion may also be attracted towards $\mathrm{BO}_{3}$ units leading to the construction of tetrahedral borate units or it may be taken up by the $\mathrm{TeO}_{2}$ for construction to network structure [27]. Monsour[20] studied $\mathrm{Na}_{2} \mathrm{O}-\mathrm{B}_{2} \mathrm{O}_{3}-\mathrm{TeO}_{2}$ glass system through FTIR spectroscopy and conform that that these glasses has high rich of B-O-Te bonds. In the present glasses when $\mathrm{NaF}_{2}$ replaced with $\mathrm{NaO}$, fluorine ions will enters interstitial spaces of the network and breaking B-O-Te bonds which results decreasing density of the present glasses. In the present glass system, the variation of molar volume as a function of $\mathrm{NaF}_{2}$ content is also illustrated in figure 2 . Since the behavior of molar volume mainly depends on the density of the glass and hence the variation of molar volume in these glasses is as expected.

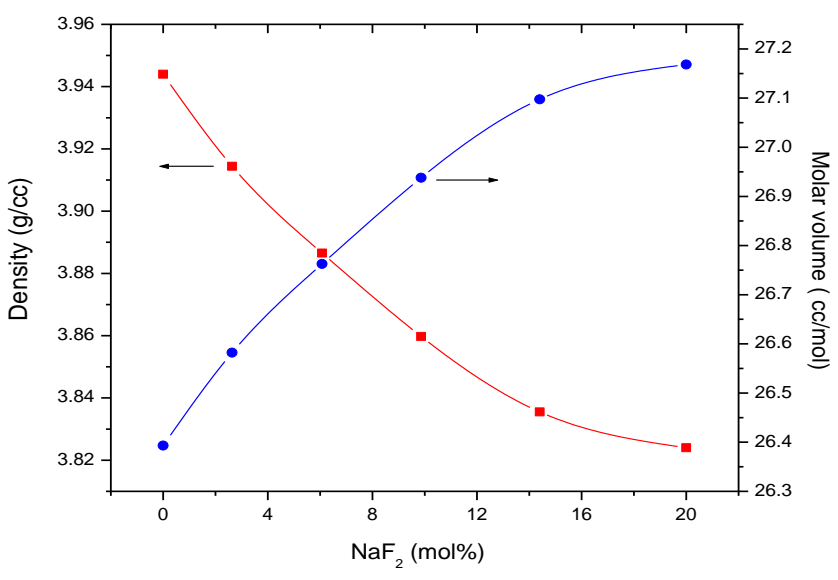

Figure 2. Density and Molar volume of the present glasses

The differential scanning calorimetry (DSC) is used to characterize the glass and to determine the thermodynamical parameters. The DSC thermograms of all the glass samples are shown in figure 3 . The glass transition temperatures $\left(\mathrm{T}_{\mathrm{g}}\right)$ and onset of crystallization temperate $\left(T_{c}\right)$ were determined based on the DSC curves using the onset method. The glass transition temperature $T_{g}$ was taken as the temperature corresponding to the intersection of the two linear portions adjoining the transition elbow in the DSC traces. The uncertainty in $\mathrm{T}_{\mathrm{g}}$ and $\mathrm{T}_{\mathrm{c}}$ is $\pm 0.1^{\circ} \mathrm{C}$. The glass stability $\mathrm{S}$ was determined by using the formula $S=T_{c}-T_{g}$. The determined values of $T_{g}, T_{c}$ and $S$ were presented table 1 . The glass transition temperature decreases from 426.2 to $344.3{ }^{\circ} \mathrm{C}$. The crystallization onset temperature is also shifted to lower temperature range from 496.3 to $459.7^{\circ} \mathrm{C}$. The glass stability (S) varies in the range 70 to $115{ }^{\circ} \mathrm{C}$ and is large enough to obtain stable glass. Figure 4 plots the variation of $\mathrm{T}_{\mathrm{g}}, \mathrm{T}_{\mathrm{c}}$ and $\mathrm{S}$ as a function of $\mathrm{NaF}_{2}$ content. The reduction in glass transition temperature and onset of crystallization can be summarized as follows:

The reduction in glass transition temperature in present glass may be due to the fact that the fluorine has a higher electronegative than oxygen, it would be expected that the substitution of fluoride ions for oxide ions decrease glass transition temperature and deformation temperature. Since two fluoride ions are substituted for an oxide ion, which causes the breakdown of the glass network structure and the fluorine atoms are introduced in oxide network can be considered not to act as bridge between two tellurium atoms because of single valence of fluorine. Breaking the oxide network, the cross linking degree of the glass former could be reduced which results in decrease of both $\mathrm{T}_{\mathrm{g}}$ and $\mathrm{T}_{\mathrm{c}}$.

The learning of optical absorption is a valuable method for the analysis of optical shifts, electronic band structure in crystalline and non-crystalline materials. The optical absorption coefficient, $\alpha$, which is the relative rate of reduction in light intensity along its path of transmission. The optical absorption coefficient $\alpha$ of the studied glasses can be estimated form the optical transmittance, reflectance, and the thickness of the sample $t$ as

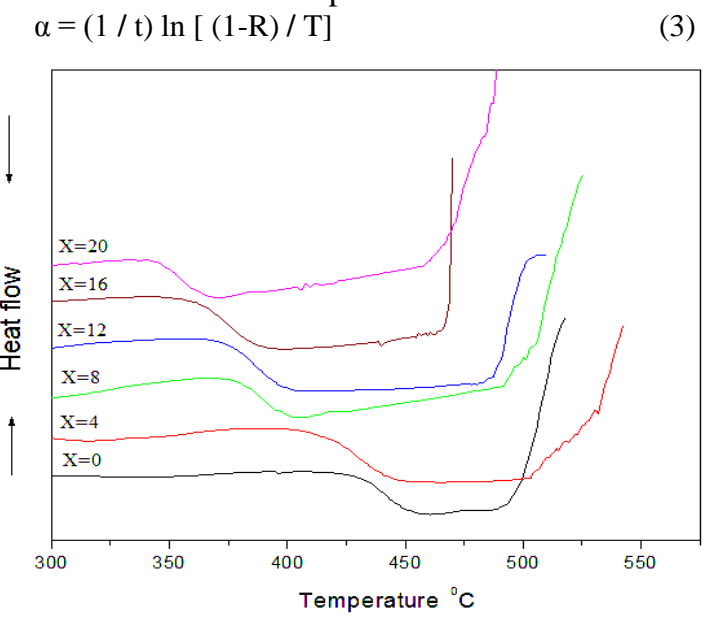

Figure 3. DSC theromogrames of the present glasses

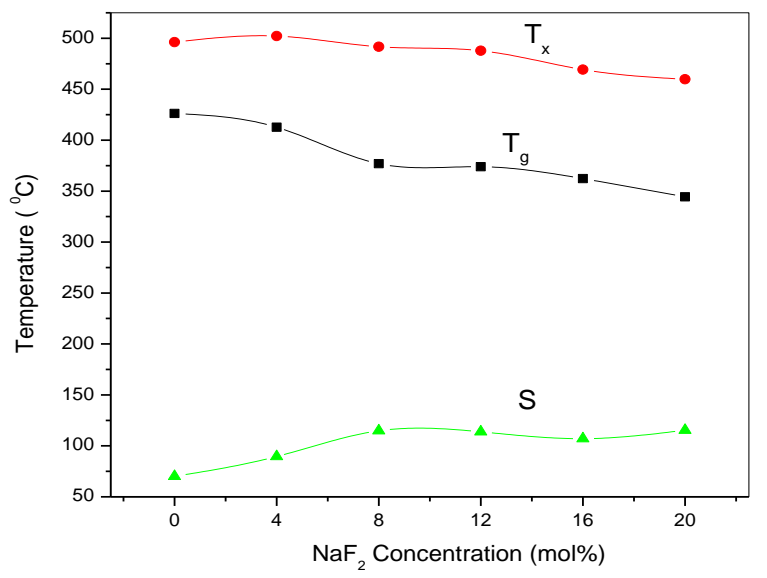

Figure 4. Variation of $\mathrm{T}_{\mathrm{g}}, \mathrm{T}_{\mathrm{c}}$ and $\mathrm{S}$ as a function of $\mathrm{NaF}_{2}$ content 
Fig 5 illustrates the UV absorption edge or the cut of wavelength of all glasses in the current study were determined are presented in Table 2 . It is observed that the UV absorption edge is increasing with $\mathrm{NaF} 2$ content from approximately $210 \mathrm{~nm}$ to $518.16 \mathrm{~nm}$.

Davis and Mott [28] and Tauc and Menth [29] relate this data to the optical band gap, Eg through the following general relation proposed for amorphous materials.

$$
(\alpha \mathrm{h} v)^{\mathrm{n}}=\mathrm{B}(\mathrm{h} v-\mathrm{Eg})
$$

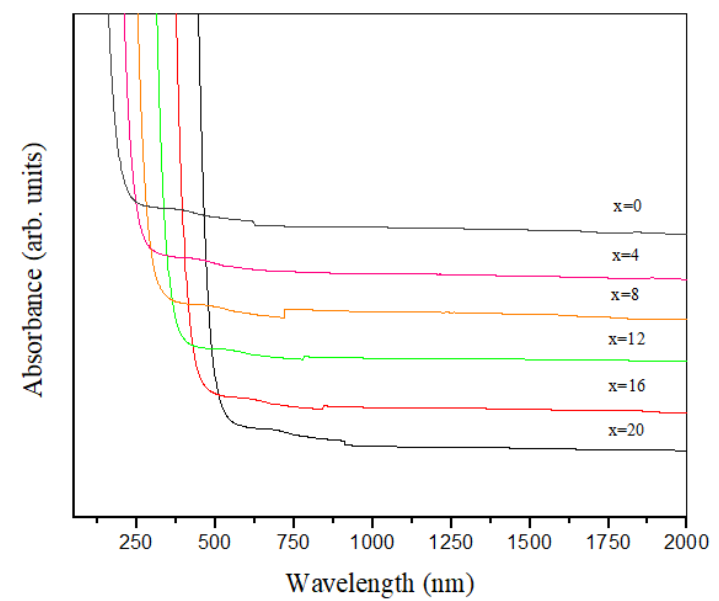

Figure 5. Optical absoprtion of present glasses

where B is a constant related to the extent of the band tailing and $\mathrm{h} v$ is incident photon energy. The index $\mathrm{n}$ determines the type of electronic transitions causing the absorption and takes the values $1 / 2,2,2 / 3$ and $1 / 3$ for indirect allowed, direct allowed, direct forbidden and indirect forbidden transitions, respectively. By plotting $(\alpha h v)^{\mathrm{n}}$ as a function of photon energy $h v$, one can find the optical energy band gap $E_{g}$ for all transitions. The values of optical band gap energy $E_{g}$ can be obtained by extrapolating the absroption coeffiect to zero absroption in the $(\alpha \mathrm{h} v)^{\mathrm{n}}$ against photon energy $\mathrm{h} v$ plots as shown in Fig 6.

The optical band gap energy thus evaluated for the glass samples at different values of $\mathrm{n}$ are listed in Table 2. Since the obtained values of the optical band gap are varying according to the selected value of the exponent $n$, one cannot really decide which value of $n$ is better to be selected. Therefore, the equation (4) may be rather used only for the determination of the type of conduction mechanism, and $E_{g}$ itself should be determined using another parameter the imaginary part of the dielectric constant, $\varepsilon_{2}$ by which the exact value of exponent can be selected. The complex refractive index and dielectric function characterize the optical properties of glass. The values of refractive index $n$ and extinction coefficient $k$ can be determined from the theory of reflectivity of light. According to this theory, the reflectance of light form a material can be expressed as [30]

$$
\mathrm{R}=\left[(\mathrm{n}-1)^{2}+\mathrm{k}^{2}\right] /\left[(\mathrm{n}+1)^{2}+\mathrm{k}^{2}\right] \text { and } \mathrm{k}=\alpha \lambda / 4 \pi
$$

where $\lambda$ is the wavelength of incident photon. The values of refractive index were estimated by using the formula $\mathrm{n}^{2}=\left(1+\mathrm{R}^{1 / 2}\right) /\left(1-\mathrm{R}^{1 / 2}\right)$

where $\mathrm{R}$ is reflectivity of the sample in the transparent region of glasses studied. Real and imaginary part of dielectric constant $\left(\varepsilon_{1}, \varepsilon_{2}\right)$ are related to the $\mathrm{n}$ and $\mathrm{k}$ values, using the formula

$$
\begin{aligned}
& \varepsilon_{1}=\mathrm{n}_{2}-\mathrm{k}_{2} \\
& \varepsilon 2=2 \mathrm{nk}
\end{aligned}
$$

Fig 7 shows the imaginary part of the dielectric constant $\varepsilon_{2}$, versus the photon energy for the studied glass system. The imaginary part of the complex index of refraction $\varepsilon_{2}$ is related to extinction coefficient, which also relates to light absorption. From the above Fig. 7, the optical band gap Eg can be obtained by extrapolating the imaginary part of dielectric constant $\left(\varepsilon_{2}\right)$ to zero as shown in the figure. On a comparison of the optical energy gap values obtained from absorption spectra in the case of indirect allowed transition are in good agreement with the values estimated from the dielectric measurements $\varepsilon_{2}$. Thus, the type of electronic transition in the present glass system is indirect allowed. In the present glasses the indirect band gap energy decreases from 1.97 to $1.52 \mathrm{eV}$ when $\mathrm{NaF}_{2}$ content increases illustrated in figure 8.

The ultraviolet transparency of borate glasses is very sensitive to the coordination of NBO's. The UV absorption involves excitation of electron from valance level of an oxygen atom to an excited energy level of same atom. The excitation energy for NBO's is lesser than that of bridging oxygens, since electrons less strongly bound with NBO's. Increasing $\mathrm{NaF}_{2}$ concentration in the present glasses causes a shift of UV absorption edge to longer wavelength (Figure 5). From above figure it is clear that increasing $\mathrm{NaF}_{2}$ content increase the UV transparency of the glasses, indicating reduction in the number of NBO's. Fluorine addition in the place of oxygen will cause a reduction in ionic conductivity, thus the role of fluorine on the conduction process can be understood by considering the formation of covalent B-F bonds, which leads to the creation of high energy network sites with the strong cation-network interaction [31,32].

When $\mathrm{TeO}_{2}$ into the $\mathrm{B}_{2} \mathrm{O}_{3}$ glass network, the concentration of $\mathrm{Na}_{2} \mathrm{O}$ which is connected with $\mathrm{B}_{2} \mathrm{O}_{3}$ network is changed and hence trigonal to tetrahedral boron ratio were formed. Then minimum number of [TeO3] units was observed for the present glass composition. The above considerations suggest that bonds of the type $\mathrm{B}-\mathrm{O}-\mathrm{Te}$ will be formed and gradual disappearance of NBOs in the whole glass network. When $\mathrm{NaF}_{2}$ introduced in glass network, fluorine ions break the network results in a depolymerization, i.e. B-O-Te [20] bonds are broken and non-bridging 
oxygen's are formed hence the decreasing band gap energy observed in the present glasses.

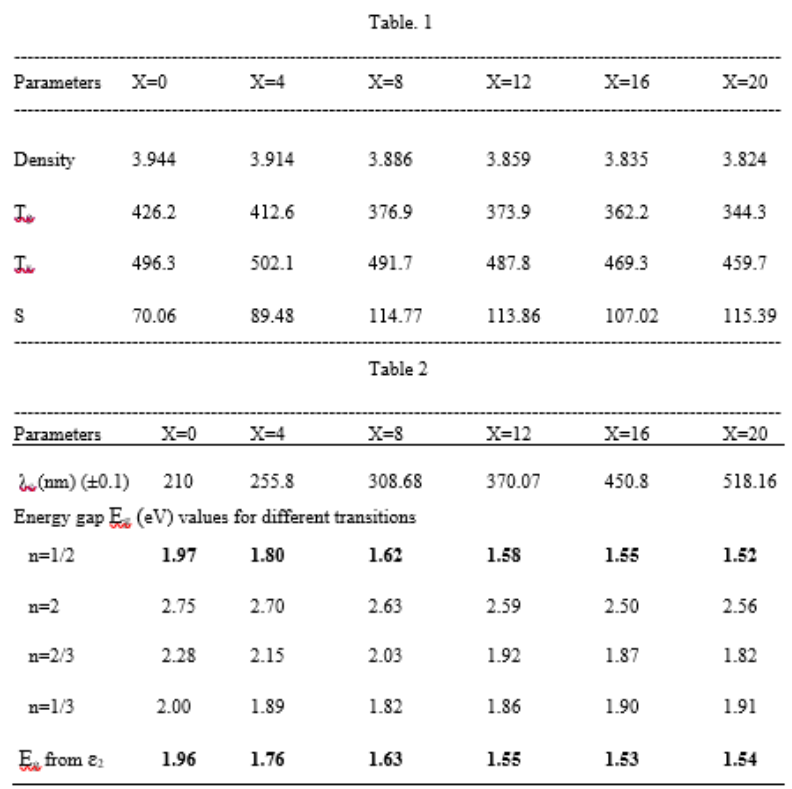

\section{CONClusions}

The following conclusions are drawn from the present study of various physical and optical properties.

The room temperature density of $\mathrm{xNaF}_{2}-(20$ x) $\mathrm{Na}_{2} \mathrm{O}-40 \mathrm{~B}_{2} \mathrm{O}_{3}-40 \mathrm{TeO}_{2}$ glasses decreased non linearly as a function of $\mathrm{NaF}_{2}$ content and the density reduction is due fluorine ions will enters interstitial spaces of the network and breaking B-O-Te bonds which results decreasing density of the present glasses.

The thermodynamically parameters such as glass transition temperature and onset of crystallization temperature of the present glasses and were found to decrease as a function of $\mathrm{NaF}_{2}$ concentration. Increasing $\mathrm{NaF}_{2}$ concentration in the present glasses causes a shift of UV absorption edge to longer wavelength indicating reduction in the number of NBO's.

When $\mathrm{NaF}_{2}$ introduced in glass network, fluorine ions break the network results in a depolymerization, i.e. B$\mathrm{O}-\mathrm{Te}$ bonds are broken and non-bridging oxygen's are formed hence the decreasing band gap energy observed in the present glasses

\section{ACKNOWLEDGMENT}

One of the authors (Boya Nagendra) wish to thank Dr. Shaik Kareem Ahmed, Asst.Professor, MJCET for providing Optical Absorption facility and DSC.
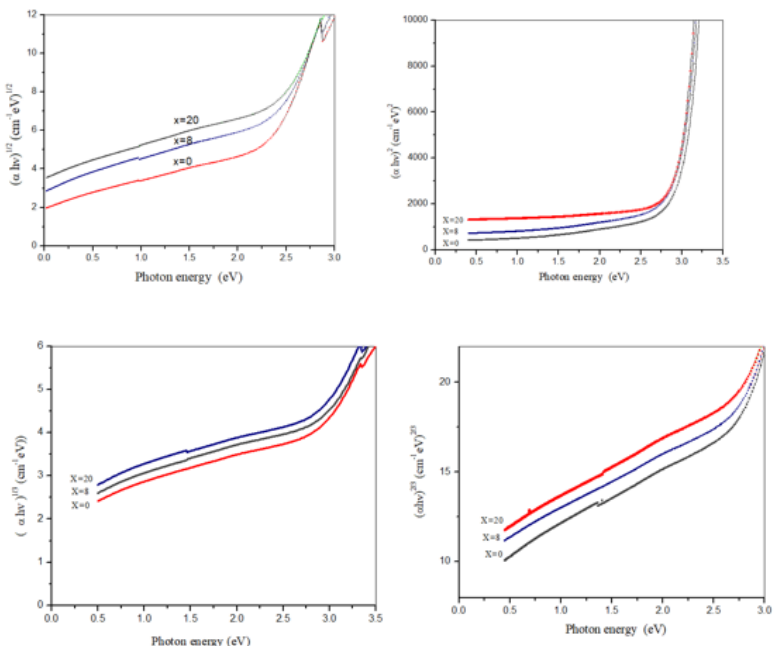

Figure 6. $(\alpha h v)^{\mathrm{n}}$ against photon energy hv of present glasses

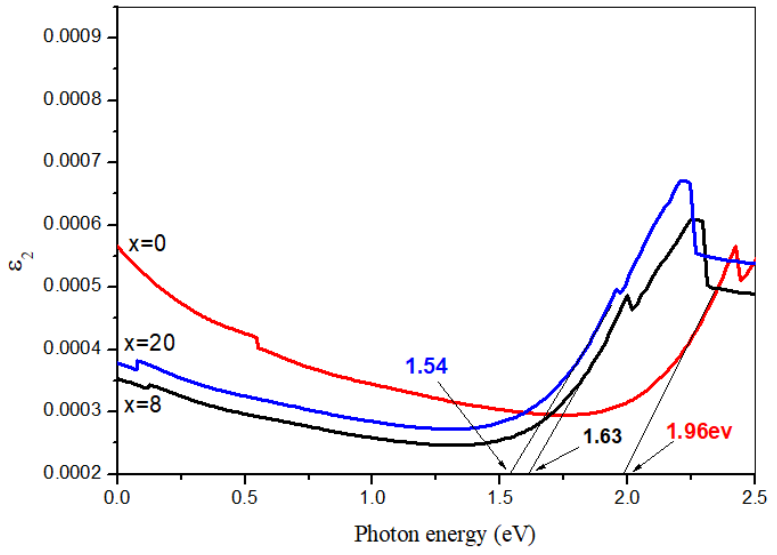

Figure 7. Imaginary part of the dielectric constant $\varepsilon_{2}$, versus the photon energy

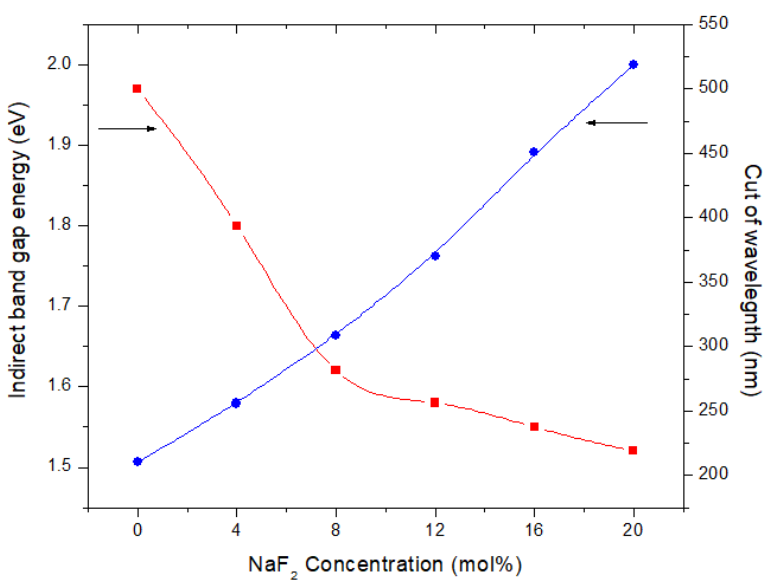

Figure 8. Variation of Indirect energy band gap and cut of wavelength with $\mathrm{NaF}_{2}$ concertation 


\section{REFERENCES}

[1] H. Nasu, O. Matsushita, K. Kamiya, H. Kobayashi and K.i. Kubodera, "Third harmonic generation from $\mathrm{Li} 2 \mathrm{O} \mathrm{TiO} 2 \mathrm{TeO} 2$ glasses" Journal of Non-Crystalline Solids, Vol.124, pp. 275-277, 1990.

[2] Li+ ion conductivities in boro-tellurite glasses, M.H. Bhat, M. Kandavel, M. Ganguli and K.J. Rao, Bulletin of Materials Science 27, 189- 198 (2004)

[3] Physical and optical properties of zinc arsenic tellurite glasses, Shaik kareem Ahmmad, M.A. Samee, A. Edukondalu, Syed Rahman, Results in physics, 2 (2012) 175-181

[4] Optical, physical and structural studies of boro-zinc tellurite glasses, P. Gayathri Pavani, K. Sadhana and V. Chandra Mouli, Physica B: Condensed Matter 406, 1242-1247 (2011).

[5] Characterization of Erbium nanoparticles doped tellurite Glass system, M. N. Azlan, M. K. Halimah, S. Z. Shafinas, and W. M. Daud, Materials Express, 5 (2015) 211-218.

[6] Thermal and optical properties of tellurite glasses doped erbium ,I. Jlassi, H. Elhouichet, and M. Ferid, 462011 (3) 806-812.

[7] Borate Materials in Nonlinear Optics, P. Becker, Adv. Mater. 10 (1999) 979-992.

[8] Structural characterization of borotellurite and aluminoborotellurite glasses, N. Kaur, A. Khanna, J. Non-Cryst. Solids 404 (2014) 116-123.

[9] Physical, structural and optical properties of erbium doped rice husk silicate borotellurite (Er-doped RHSBT) glasses, A.V. Deepa, M. Priya, S. Suresh, 11 (5) (2016) 57-63.

[10] Thermal stability and spectroscopic properties of Ho3+ doped tellurite-borate glasses, YANG Yanmin, LIU Yanzhou, CAI Peiqing, Ramzi , Hyo Jin Seo, 33 (2015) 939.

[11] Crystallization of Bi4Ti3O12 from glasses in the system Bi2O3/TiO2/B2O3, K. Gerth, C. Russesl, J. Non-Cryst. Solids 221 (1997) 10.

[12] R.A.F. El-Mallaway, Tellurite Glasses Handbook: Properties and Data, CRC, Boca Raton, FL, 2002.

[13] Tellurite glass: a new candidate for fiber devices, J.S. Wang, E.M. Vogel, E. Snitzer, Opt. Mater. 3 (1994) 187.

[14] Linear and Nonlinear Optical Properties of TeO2 Glass, S.H. Kim, T. Yoko, S. Sakka, J. Am. Ceram. Soc. 76 (1993) 865.

[15] Borosilicate glasses for nuclear waste immobilization, M. J. Plodinec, Glass Technol. 41, 186-192 (2000).

[16] K. Meshkovski., Composite Optical Materials Based on Porous Matrices St. Petersburg, 1998.

[17] Thermophysical characteristics of glasses based on the Na2O-B2 O3 - SiO2 system, T. V. Antropova, S. V. Stolyar, V. L. Stolyarova, K.A Tsapko, J. Optical Technology 69(3) (2002) 207208.

[18] Structural study of $\mathrm{Na2O}-\mathrm{B2O}-\mathrm{OiO} 2$ glasses from molecular simulations using a polarizable force field, Fabien Pacaud, JeanMarc Delaye, , Thibault Charpentier, Laurent Cormier, Mathieu Salanne The Journal of Chemical Physics 147, (2017) 161711.

[19] Glass - Forming Ability and Crystallization Tendency Evaluated by the DTA Method in the Na2O-B2O3-Al2O3 System, Takashi Wakasugi, Rikuo Ota, and Jiro Fukunaga, J. American ceramic society $75[11] 3129$

[20] FTIR spectra of pseudo-binary sodium borate glasses containing $\mathrm{TeO} 2$, E. Mansour, Journal of Molecular Structure 1014 (2012) 1 6

[21] A spectroscopic study of fluoride containing sodium borate glasses, Kamitsos and Karakassids, solid state ionics, 28-30 (1988) 783787.

[22] Synthesis and structural studies of Na2O-ZnO-ZnF2-B2O3 oxyfluoride glasses, Shantala D patil, V. M jali, R.V Anavekar, Bull. Mater. Sci, 31 (2008) 631-634.
[23] Properties and structure of NaF-Na2O-B2O3 glasses, J.E. Shelby, R.L. Ortolano, Phys. Chem. Glasses 31 (1990) 25.

[24] Structural, optical and thermal investigations on Dy3+ doped $\mathrm{NaF}-\mathrm{Li2O}-\mathrm{B} 2 \mathrm{O} 3$ glasses, R.T.Karunakaran, K.Marimuthu, S.Surendra Babu, S. Arumugam, Physica B 404 (2009) 39954000.

[25] Dysprosium doped alkali fluoroborate glasses-Thermal, structural and optical investigations, R.T.Karunakaran, K.Marimuthu, S.Surendra Babu, S.Arumugam, Journal of Luminescence 130 (2010) 1067-1072

[26] Spectroscopic and glass transition investigations on Nd3+-doped $\mathrm{NaF}-\mathrm{Na2O}-\mathrm{B} 2 \mathrm{O} 3$ glasses, B. Karthikeyana, S. Mohan, Materials Research Bulletin 39 (2004) 1507-1515.

[27] Structural investigations of sodium diborate glasses containing $\mathrm{PbO}, \mathrm{Bi} 2 \mathrm{O} 3$ and TeO2: Elastic property measurements and spectroscopic studies, V.C. Veeranna Gowda, C. Narayana Reddy, K.C. Radha, R.V. Anavekar, J Etourneau, K.J. Rao, J. Non-Cryst. Solids 353 (2007) 1150-1163.

[28] Conduction in non-crystalline systems V. Conductivity, optical absorption and photoconductivity in amorphous semiconductors, E A Davis, N.F.Mott, Phil. Mag. 22 (1970) 903.

[29] States in the gap, J Tauc, A. Menth, J. Non-Cryst. Solids 8 (1972) 569.

[30] D.P. Gosain, T. Shimizu, M. Ohmura, M. Suzuki, T. Bando, S.Okano, J. Mater. Sci. 26(12) (1991) 2371.

[31] A spectroscopic study of fluoride containing sodium borate glasses, E.I Kimitsos and M.A Karakassides, Solid state Ionics 28-30 (1988) 783-787

[32] FT-IR and Raman spectroscopic studies of $\mathrm{ZnF2-ZnO-As2O3-}$ $\mathrm{TeO} 2$ glasses, Shaik Kareem Ahmmad, MA Samee, SM Taqiullah, Syed Rahman, J. Taibah university for science 10 (2016) 329339. 